\title{
10-year risk of stroke in patients with previous cerebral infarction and the impact of carotid surgery in the Asymptomatic Carotid Surgery Trial (ACST-1)
}

\begin{tabular}{|r|l|}
\hline Journal: & International Journal of Stroke \\
\hline Manuscript ID & IJS-01-16-4730.R1 \\
\hline Manuscript Type: & Research \\
\hline Date Submitted by the Author: & n/a \\
\hline Complete List of Authors: & $\begin{array}{l}\text { Streifler, Jonathan; Tel Aviv University, Neurology Unit } \\
\text { den Hartog, Anne; Utrecht medical centre, Department of Surgery } \\
\text { Pan, Samuel; University of Oxford, CTSU, Nuffield Department of } \\
\text { Population Health } \\
\text { Pan, Hongchao; University of Oxford, CTSU, Nuffield Department of } \\
\text { Population Health } \\
\text { bulbulia, richard; University of Oxford, CTSU, Nuffield Department of } \\
\text { Population Health } \\
\text { Thomas, Dafydd; Imperial College London } \\
\text { Brown, Martin M; Institute of Neurology, Brain Repair and Rehabilitation } \\
\text { Halliday, Alison; University of Oxford, Nuffield Department of Surgery }\end{array}$ \\
\hline Keywords: & $\begin{array}{l}\text { Asymptomatic carotid stenosis, Carotid endarterectomy, Ischaemic stroke, } \\
\text { Clinical trial, Prevention, Risk factors }\end{array}$ \\
\hline \multicolumn{2}{|c}{} \\
\hline
\end{tabular}


10-year risk of stroke in patients with previous cerebral infarction and the impact of carotid surgery in the Asymptomatic Carotid Surgery Trial (ACST-1)

Jonathan Y. Streifler ${ }^{1}$, Anne G. den Hartog ${ }^{2}$, Samuel Pan ${ }^{3}$, Hongchao Pan ${ }^{3}$, Richard Bulbulia ${ }^{3}$, Dafydd J. Thomas ${ }^{4}$, Martin M Brown ${ }^{5}$, Alison Halliday ${ }^{6}$ on behalf of the ACST-1 trial collaborators

${ }^{1}$ Neurology Unit, Rabin Medical Center, Golda Campus, Petach Tikva and Tel Aviv University, Tel Aviv, Israel

${ }^{2}$ Department of Vascular Surgery, UMC Utrecht, Utrecht, the Netherlands

${ }^{3}$ Clinical Trial Service Unit, Nuffield Department of Population Health, University of Oxford, UK

${ }^{4}$ Department of Neurology, Imperial College, London, UK

${ }^{5}$ UCL Institute of Neurology, London

${ }^{6}$ Nuffield Department of Surgery, University of Oxford, UK

Corresponding author: A Halliday, University of Oxford alison.halliday@nds.ox.ac.uk

22 November 2015 


\section{Abstract}

Background: Silent brain infarcts are common in patients at increased risk of stroke and are associated with a poor prognosis. In patients with asymptomatic carotid stenosis similar adverse associations were claimed, but the impact of previous infarction or symptoms on the beneficial effects of carotid endarterectomy (CEA) is not clear. Our aim was to evaluate the impact of prior cerebral infarction in patients enrolled in the Asymptomatic Carotid Surgery Trial (ACST-1), a large trial with 10-year follow-up in which participants whose carotid stenosis had not caused symptoms for at least 6 months were randomly allocated either immediate or deferred CEA.

Methods: ACST-1 included 3120 patients. Of these, 2333 patients with baseline brain imaging were identified and divided into 2 groups irrespective of treatment assignment, 1331 with evidence of previous cerebral infarction, defined as a history of ischaemic stroke or TIA >6 months prior to randomization or radiological evidence of an asymptomatic infarct (Group 1) and 1002 with normal imaging and no prior stroke or TIA (Group 2). Stroke and vascular death were compared during follow-up and the impact of CEA was observed in both groups.

Results: Baseline characteristics of patients with and without baseline brain imaging were broadly similar. Of those included in the present report, male gender and hypertension were more common in Group 1 while mean ipsilateral stenosis was slightly greater in Group 2. At 10 years follow-up, stroke was more common among participants with cerebral infarction before randomization (absolute risk increase [ARI] 5.8\% [1.8-9.8], $p=0.004$ ) and risk of stroke and vascular death was also higher in this group (ARI 6.9\% [1.9-12.0], p=0.007). On multivariate analysis, prior cerebral infarction was associated with a greater risk of stroke 
$(\mathrm{HR}=1.5195 \% \mathrm{Cl}: 1.17-1.95, \mathrm{p}=0.002)$ and of stroke or other vascular death $(\mathrm{HR}=1.30$ 95\% $\mathrm{Cl}: 1.11-1.52, \mathrm{p}=0.001)$.

At 10 years, greater absolute benefits from immediate CEA were seen in those patients with prior cerebral infarction $(6.7 \%$ strokes immediate CEA vs. $14.7 \%$ delayed CEA; HR 0.47 [0.34-0.65]; $p=0.003$ ), compared to those lower risk patients without prior cerebral infarction (6.0\% vs. 9.9\% respectively; HR 0.61 [0.39-0.94]; $p=0.005)$, though it must be emphasized that ACST-1 was not designed to test this retrospective and non-randomized comparison.

Conclusions: Asymptomatic carotid stenosis patients with prior cerebral infarction have a higher stroke risk during long-term follow-up than those without prior cerebral infarction. Evidence of prior ischemic events might help identify patients in whom carotid intervention is particularly beneficial. 


\section{Introduction}

The term "silent brain infarcts" is widely used to describe brain infarcts seen on brain Computed Tomography (CT) or Magnetic Resonance Imaging (MRI) without any corresponding clinical symptoms. These lesions are common, especially on brain MRI, ranging from $20 \%$ in the general elderly population to up to $50 \%$ in patients at high risk of stroke.(1) Silent cerebral infarction is associated with poor outcome in most studies, with around a two-fold increase in the risk of stroke.(1) Earlier studies reported $23 \%$ patients with asymptomatic significant carotid stenosis had silent cerebral infarction on brain MRI (2) (and $15-18 \%$ on CT scans) $(3,4)$ but the importance of such lesions was unclear. $(4,5)$ Whilst one study (5) concluded that carotid endarterectomy (CEA) for asymptomatic stenosis patients with silent cerebral infarction might not be justified, a later one (4) suggested that silent cerebral infarction ipsilateral to an asymptomatic stenosis could help identify a high stroke-risk group and might prove useful in selecting appropriate patients for CEA. In the NASCET trial the presence of ipsilateral cerebral infarction on CT in patients presenting with transient ischemic attacks (TIA's) did not affect their prognosis, (6) but, in another, more recent study, brain lesions (mainly on MRI's) were found to be important in identifying TIA patients at higher stroke risk. (7)

The aim of our study was to investigate, in a large group of asymptomatic carotid stenosis patients with long-term follow-up drawn from the Asymptomatic Carotid Surgery Trial-1 (ACST-1), whether cerebral infarction at admission to the study was associated with poorer outcomes compared with patients with normal brain imaging. ACST-1, with large numbers of patients and 10-year follow-up allows uniquely reliable assessment of this outcome. 


\section{Materials and methods}

Details of the ACST-1 trial have been published previously.(8, 9) Between 1993 and 2003, 3120 patients with high grade unilateral or bilateral asymptomatic carotid artery stenosis whose carotid stenosis has not caused symptoms for at least 6 months and who had no past history of ipsilateral disabling or severe contralateral stroke were randomly allocated to either immediate CEA or deferral of surgery until it appeared to be more clearly indicated. The aim of the trial was to determine whether immediate CEA and best current medical treatment improved stroke free survival when compared with best medical treatment alone (deferred CEA being undertaken as needed).

Patients' comorbidities (including hypertension, diabetes, and coronary artery disease) and concurrent medications (including antiplatelet therapy, anticoagulants and statin use) were recorded prospectively. Carotid artery stenosis was measured by Doppler ultrasound and recorded as percentage luminal diameter reduction, usually rounded to the nearest decile. Whilst some form of baseline brain imaging (CT or MRI) was often undertaken, it was not a requirement for randomization, and around one quarter of trial participants had no prerandomization scans. For those patients who had brain scans, presence or absence of ipsilateral, contralateral, bilateral or vertebrobasilar infarcts was recorded by the investigator at baseline. During follow-up, information regarding any CEA, perioperative morbidity, stroke, death, blood pressure, and current drug treatment was recorded. Annual carotid ultrasound was requested for the first 5 years after randomization.

Primary trial outcomes were perioperative mortality and morbidity (death or stroke within 30 days of CEA) and non-peri-operative stroke. Events were adjudicated centrally by members of the endpoint review committee, who were blinded to treatment allocation. Strokes were classified according to location (ipsilateral, contralateral, vertebrobasilar), cause 
(haemorrhagic, probably cardioembolic, other ischaemic [lacunar]) and outcome after 6 months (ie, non-disabling, disabling, fatal). Most analyses were of first strokes; analyses of further worst strokes counted patients only once, and fatal strokes were those that caused death directly or indirectly. $(8,9)$

\section{Design of this study}

Previous cerebral infarction was defined as a history of ischaemic stroke or TIA in any territory occurring $>6$ months prior to randomization or radiological evidence of an asymptomatic, or 'silent' brain infarct. Patients fitting this definition were included in Group 1 (relevant symptoms reported at baseline are shown in Table 1), and those without previous cerebral infarction were included in Group 2. Patients with prior stroke or TIA were included in Group 1 even if their imaging was reported as normal. We excluded patients with no imaging before inclusion who were free of previous events.

\section{Statistical analysis}

Using minimised randomisation patients were allocated to immediate CEA or deferral of any carotid surgery. Analyses of the effects of immediate versus deferred carotid surgery in both groups were by original treatment allocation (ie, intention-to-treat). Baseline differences between the two groups were examined with Pearson Chi-square test for binominal variables, and Student's t-test for continuous variables. A Cox proportional hazard model was calculated to assess the independent association between type of stroke or cause of death for the two groups thereby correcting for baseline differences and potential confounders. 
Differences in clinical outcome (stroke, and a composite outcome of any stroke or vascular death) between the two groups were assessed with Cox regression survival analyses and separated by baseline characteristics.

\section{Results}

Of the 3120 participants, 787 patients had no imaging at study entry and were excluded. Their characteristics were quite similar to the included patients (Table S1) apart from higher rates of known cardiac diseases and of significant contralateral stenosis. Ipsilateral stenosis was somewhat more severe in the analyzed group (only in categorical, not linear analysis) as was male gender. As previously described, pre-randomization brain imaging was left to the clinicians' discretion, and rates of such imaging ranged from almost $90 \%$ in countries such as Italy, Israel, Germany and former Yugoslavia to about $20 \%$ in some UK and Swedish centers.

Of the 2333 patients included in the present report, 1331 had previous cerebral infarction (Group 1) and 1002 had no infarction (Group 2). Only 30 patients were included in Group 1 because of previous symptoms yet normal brain imaging. Patients' characteristics are shown in Table 2. There were more men in Group 1 but most risk factors were equally distributed (apart from hypertension which was commoner in Group 1). Severity of carotid stenosis was somewhat greater in those without brain lesions. Allocation to immediate CEA was around $50 \%$ in both groups (Table 2).

Stroke outcome events and death outcome events are shown in Table 3 and Table S2 respectively. As expected in patients with carotid disease, most strokes were ischaemic, arterial in origin and affected the carotid territory. About two thirds of carotid territory strokes in both groups were ipsilateral to the randomised artery. There were more carotid and vertebrobasilar territory strokes in Group 1, whilst the rates of hemorrhagic, lacunar and 
cardio-embolic strokes were lower in both groups. Disabling strokes were twice as common in Group 1.

Stroke risk analysis is shown in Figure 1. At 10 years, stroke risk in Group 1 was significantly higher than in Group 2 (absolute risk increase [ARI] of 5.8\% (95\% Cl 1.8-9.8), relative risk increase $[\mathrm{RRI}$ 51\% [fully adjusted hazard ratio $\mathrm{HR}=1.51(95 \% \mathrm{Cl} 1.17-1.95)$, $p=0.002])$.

About $40 \%$ of patients in both groups died within 10 years (Table S2). Prior cerebral infarction were associated with an increased risk of fatal stroke (61 [4.6\%] in group 1 vs 29 [2.9\%] in group 2; $p=0.009)$ and of strokes or vascular death (ARI 6.9\% (1.9-12.0), $p=0.007$, RRI 30\% [HR= $1.30(95 \% \mathrm{Cl} 1.11-1.52), p=0.0009])$ (Figure 2).

In Table 4 (hazard ratio of stroke by patients' characteristics and risk factors) early CEA reduced stroke risk in both uni- and multivariable analyses, increasing age and presence of diabetes were independent risk factors for stroke, and prior cerebral infarction was a strong predictor of future stroke in the multivariable analyses. In Table S3 (analysis of stroke and vascular death by risk factors), male gender and presence of cardiac disease as well as the presence of prior cerebral infarction were important.

When comparing effects of CEA in stroke prevention for each group, benefit of surgery was clear for both groups within 5 years, with greater absolute benefits of immediate CEA seen in those patients with prior brain infarcts. In this group, there were 45/676 (6.7\%) strokes in the immediate group vs. 96/653 (14.7\%) in the delayed group; HR 0.47 (0.34-0.65); $p=0.003$, compared to those lower risk patients without prior brain infarcts $(29 / 484$ [6.0\%] vs. 51/516 [9.9\%] respectively; HR 0.61 [0.39-0.94]; $p=0.005)$. This greater absolute benefit was chiefly due to the higher underlying risk of stroke in the prior cerebral infarction group (5-year gain $4.9 \%, p=0.005 \%$ vs. $3.9 \%, p=0.02 \%$ ), but also the larger relative risk reduction in stroke risk associated with allocation to immediate CEA observed in those with prior 
cerebral infarction. It should be emphasized that ACST-1 was not originally designed to test this retrospective and non-randomized comparison.

\section{Discussion}

These findings, in a large trial of patients with currently asymptomatic carotid stenosis, have shown that, although presently without symptoms, the finding of prior cerebral infarction (the vast majority of which were clinically silent), was associated with a significant increase in stroke risk and in deaths from stroke and vascular disease.

In an older study (5), between 1986-1995, 301 asymptomatic carotid stenosis patients had CEA; prior to their surgery $34 \%$ of these patients had silent cerebral infarction. They were followed for a mean of just over 5 years and no significant difference was observed between the group with silent cerebral infarction and those without, either in perioperative morbidity, or in long-term mortality ( $22 \%$ vs. $15 \%$ p $=0.1)$. Late strokes were more common in silent cerebral infarction patients $(11 \%$ vs. $3 \%, p=0.006)$ and both lacunar and nonlacunar infarcts were independent predictors of such events. The authors concluded that because silent cerebral infarction predicted poor stroke outcome (mostly unrelated to the diseased artery), a less aggressive attitude toward CEA in such patients might be justified. However, the present report shows that most strokes in patients with prior cerebral infarction were ischaemic, of arterial origin and in the carotid territory (two-thirds ipsilateral), suggesting that atherothrombosis of the carotid artery is a major source of continued stroke risk that could be significantly reduced by early intervention. Within 5 years, patients both with and without prior cerebral infarction benefitted from immediate CEA, but the former received greater absolute benefits.

Results from the Asymptomatic Carotid Stenosis and Risk of Stroke (ACSRS) study,(4) which began at the same time as ACST-1, are consistent with our findings (5): ACSRS 
studied the natural history of asymptomatic carotid stenosis and followed 821 patients, who were not intended to have an operation, for a mean of 44.6 months. The investigators were principally interested in endpoints ipsilateral to the stenosed artery and in new silent cerebral infarction, considered to be embolic, which were identified ipsilateral to the side of the stenosis in $17.8 \%$ of the patients. At the end of follow-up the annual ipsilateral stroke rate was $4.6 \%$ in those with silent cerebral infarction, compared with $2.4 \%(p=0.032)$ and this difference was more pronounced in patients with tighter stenoses (over 60\%), including those with $60-79 \%$ stenosis. The authors concluded that patients with silent cerebral infarction were at increased risk of stroke and more likely to benefit from surgical intervention.(4) A recent review of the significance of silent cerebral infarction in asymptomatic carotid stenosis patients focused mainly on underlying aetiologies and likely mechanisms responsible for silent cerebral infarction(10). The authors concluded that micro-embolic signals (detected by transcranial Doppler) were the most important factor determining future stroke risk and that only silent cerebral infarction (cortical or subcortical) in the ICA territory was of prognostic significance.

Our study is the largest study to prospectively assess the importance of prior cerebral infarction in patients with currently asymptomatic carotid artery stenosis, and has uniquely long follow-up. We have also shown that, whilst CEA reduces future stroke risks in such patients, prior brain infarction, especially in unoperated asymptomatic carotid stenosis patients, is an independent risk factor for future stroke and vascular death.

Our study has some limitations: a significant number of patients did not have CT scan prior to randomization; their baseline characteristics, however, were broadly similar, and the presence or lack of baseline imaging was largely determined by centre location rather than individual participants' features. The "best medical therapy" used during the trial study 
period has previously been discussed $(8,9)$. Use of statins (and other cardio-vascular protective medications) significantly increased throughout the later years of the study; whilst we have shown that use of statins reduced overall stroke risk, the additional benefit of surgery (ARR 7\%) was unaffected by statin use and persisted out to 10 years. [9] More recent observational studies of patients with high grade asymptomatic carotid stenosis are too small to provide reliable evidence on the effect of intensive risk factor modification on the current stroke risk associated with such lesions.(11) However, several studies are planned or ongoing which directly compare carotid intervention plus CMT versus CMT alone; these will report in the early 2020s and should clarify the role of carotid intervention in such patients.

The challenge facing clinicians now, when considering how best to treat patients with asymptomatic carotid stenosis, is to identify those most at risk of stroke in whom the periprocedural risks of carotid intervention are justified. (12-14) Our study demonstrates that in ACST-1, patients both with and without prior cerebral infarction benefit from CEA regardless of brain imaging findings. However, since prior cerebral infarction is associated with a marked increase in stroke risk without intervention, the benefits of surgery are greater in this group of patients. Accordingly, a history of cerebral symptoms, or imaging to detect prior 'silent' cerebral infarction could be helpful when selecting patients for early intervention. Nonetheless, such patients should also receive intensive and comprehensive risk factor management in an attempt to reduce their overall risk of cardiovascular complications and early death. $(11,12)$ 


\section{Acknowledgements}

The ACST trial was funded by the UK Medical Research Council, The Stroke Association and the BUPA Foundation. Statistical support was provided by the Clinical Trial Service Unit, Department of Population Health in Oxford. The ACST-1 trial collaborators and Trial Committees were reported previously. ${ }^{8}$ Professor Halliday's research is funded by the National Institute of Healthcare Research Oxford Biomedical Research Centre Programme.

\section{Authors' contributions}

$\mathrm{AH}$ (principal investigator) and DT designed ACST-1, and with JS and MB participated in study conduct and long-term follow-up of patients. JS, AdH, AH, SP, HP and RB did the analysis and drafted the report, which all authors revised.

\section{Conflicts of interest}

We declare that we have no conflicts of interest

\section{Ethics approval}

Ethics approval granted by North West Thames Research Ethics Committee 


\section{References:}

1. Vermeer SE, Longstreth WT Jr., Koudstaal PJ. Silent brain infarcts: a systematic review. Lancet Neurol. 2007;6:611-9.

2. Mathiesen EB Waterloo K, Joakimsen O, Bakke SJ, Jacobsen EA, Bønaa KH. Reduced neuropsychological test performance in asymptomatic carotid stenosis: The Tromsø Study. Neurology 2004;62:695-701

3. Brott T, Tomsick T, Feinberg W, Johnson C, Biller J, Broderick J, et al. Baseline silent cerebral infarction in the Asymptomatic Carotid Atherosclerosis Study. Stroke $1994 ; 25: 1122-9$.

4. Kakkos SK, Sabetai M, Tegos T, Stevens J, Thomas D, Griffin M, et al; Asymptomatic Carotid Stenosis and Risk of Stroke (ACSRS) Study Group. Silent embolic infarcts on computed tomography brain scans and risk of ipsilateral hemispheric events in patients with asymptomatic internal carotid artery stenosis. $\mathrm{J}$ Vasc Surg. 2009;49:902-9.

5. Cao P, Zannetti S, Giordano G, De Rango P, Parlani G, Caputo N. Cerebral tomographic findings in patients undergoing carotid endarterectomy for asymptomatic carotid stenosis: short-term and long-term implications. J Vasc Surg. 1999;29:995-1005.

6. Eliasziw M, Streifler JY, Spence JD, Fox AJ, Hachinski VC, Barnett HJ. Prognosis for patients following a transient ischemic attack with and without a cerebral infarction on brain CT. North American Symptomatic Carotid Endarterectomy Trial (NASCET) Group. Neurology 1995;45:428-31.

7. Merwick A, Albers GW, Amarenco P, Arsava EM, Ay H, Calvet D, et al. Addition of brain and carotid imaging to the $A B C D^{2}$ score to identify patients at early risk of stroke 
after transient ischaemic attack: a multicentre observational study. Lancet Neurol. 2010;9:1060-9

8. Halliday A, Mansfield A, Marro J, Peto C, Peto R, Potter J, et al on behalf of the MRC Asymptomatic Carotid Surgery Trial (ACST) Collaborative Group. Prevention of disabling and fatal strokes by successful carotid endarterectomy in patients without recent neurological symptoms: randomised controlled trial. Lancet 2004;363:1491502

9. Halliday A, Harrison M, Hayter E, Kong X, Mansfield A, Marro J, et al on behalf of the Asymptomatic Carotid Surgery Trial (ACST) Collaborative Group. 10-year stroke prevention after successful carotid endarterectomy for asymptomatic stenosis (ACST-1): a multicentre randomised trial. Lancet 2010;376:1074-84.

10. Jayasooriya G, Thapar A, Shalhoub J, Davies AH. Silent cerebral events in asymptomatic carotid stenosis. J Vasc Surg. 2011;54:227-36.

11. Marquardt L, Geraghty OC, Mehta Z, Rothwell PM. Low Risk of Ipsilateral Stroke in Patients With Asymptomatic Carotid Stenosis on Best Medical Treatment. A Prospective, Population-Based Study. Stroke. 2010;41:e11-e17.

12. Streifler JY. Asymptomatic carotid stenosis: intervention or just stick to medical therapy- the case for medical therapy. J Neural Transm. 2011;118:637-40.

13. Vikatmaa P, Mitchell D, Jensen LP, Beiles B, Biörck M, Hallbakken E et al. Variation in clinical practice in carotid surgery in nine countries 2005-2010. Lessons from VASCUNET and recommendations for the future of national clinical audit. Eur J Vasc Endovasc Surg, 2012;44:11-17

14. De Rango P. Carotid stenosis: An unknown disease... Eur J Vasc Endovasc Surg, $2012 ; 44: 18-19$ 
Table 1: Symptoms in Group 1 (clinical or radiological evidence of cerebral infarction)

\begin{tabular}{lll}
\hline & $\mathbf{N}=1331$ \\
& $\mathbf{n}(\%)$ & \\
\hline Ipsilateral & silent brain infarct & $898(67.47)$ \\
& amaurosis fugax & $67(5.03)$ \\
& cortical TIA & $131(9.84)$ \\
& stroke & $121(9.09)$ \\
other / unknown symptoms & $114(8.56)$ \\
& & \\
\hline Contralateral & silent brain infarct & $466(35.01)$ \\
amaurosis fugax & $164(12.32)$ \\
\hline cortical TIA & $348(26.15)$ \\
stroke & $331(24.87)$ \\
other / unknown symptoms & $22(1.65)$ \\
\hline
\end{tabular}


Table 2: Baseline characteristics of group 1 (symptoms or infarcts) vs group 2 (no symptoms or infarcts)

\begin{tabular}{|c|c|c|c|c|c|}
\hline \multirow{2}{*}{ Category } & \multicolumn{2}{|c|}{$\begin{array}{c}\text { Group } 1 \\
(1331)\end{array}$} & \multicolumn{2}{|c|}{$\begin{array}{c}\text { Group } 2 \\
(1002)\end{array}$} & \multirow[t]{2}{*}{ P-value } \\
\hline & $\mathrm{n}$ & $\%$ & $n$ & $\%$ & \\
\hline Sex & & & & & 0.002 \\
\hline Men & 922 & $(69.3)$ & 632 & (63.1) & \\
\hline Women & 409 & $(30.7)$ & 370 & $(36.9)$ & \\
\hline Age at entry (years) & & & & & 0.2 \\
\hline$<65$ & 407 & $(30.6)$ & 272 & $(27.2)$ & \\
\hline $65-74$ & 651 & $(48.9)$ & 513 & $(51.2)$ & \\
\hline$\geq 75$ & 273 & $(20.5)$ & 217 & $(21.7)$ & \\
\hline mean $\pm S D$ & 68.5 & \pm 7.6 & 68.8 & 37.6 & 0.2 \\
\hline \multicolumn{5}{|c|}{ Ipsilateral carotid diameter reduction (\% by ultrasound) } & 0.02 \\
\hline$<80$ & 569 & $(42.8)$ & 373 & $(37.2)$ & \\
\hline $80-89$ & 355 & $(26.7)$ & 282 & $(28.1)$ & \\
\hline$\geq 90$ & 407 & $(30.6)$ & 347 & $(34.6)$ & \\
\hline Ispsilateral stenosis & 79.0 & \pm 11.7 & 80.2 & \pm 11.0 & 0.01 \\
\hline \multicolumn{5}{|c|}{ Contralateral stenosis $>\mathbf{5 0} \%$ (incl. occlusion) } & 0.6 \\
\hline Yes & 372 & $(28.0)$ & 269 & $(26.9)$ & \\
\hline No & 959 & $(72.1)$ & 733 & $(73.2)$ & \\
\hline Diabetes? & & & & & 1.0 \\
\hline Yes & 267 & $(20.1)$ & 202 & $(20.2)$ & \\
\hline No & 1064 & $(79.9)$ & 800 & $(79.8)$ & \\
\hline Cardiac disease? & & & & & 0.9 \\
\hline Yes & 429 & $(32.2)$ & 320 & $(31.9)$ & \\
\hline No & 902 & $(67.8)$ & 682 & $(68.1)$ & \\
\hline Hyperlipidemia? & & & & & 0.6 \\
\hline Yes & 1033 & $(77.6)$ & 787 & $(78.5)$ & \\
\hline No & 298 & $(22.4)$ & 215 & $(21.5)$ & \\
\hline Hypertension? & & & & & 0.01 \\
\hline Yes & 1138 & $(85.5)$ & 818 & $(81.6)$ & \\
\hline No & 193 & $(14.5)$ & 184 & $(18.4)$ & \\
\hline Allocated Immediate CEA? & & & & & 0.3 \\
\hline Yes & 677 & $(50.9)$ & 486 & $(48.5)$ & \\
\hline No & 654 & $(49.1)$ & 516 & $(51.5)$ & \\
\hline
\end{tabular}


Table 3: Number of the first episode of stroke events observed in group 1 and 2

\begin{tabular}{|c|c|c|c|c|}
\hline Stroke type & $\begin{array}{l}\text { Both groups } \\
\begin{array}{c}(\mathrm{N}=2333) \\
\mathrm{n}(\%)\end{array}\end{array}$ & $\begin{array}{c}\text { Group } 1 \\
\text { (N=1331) } \\
\text { n (\%) }\end{array}$ & $\begin{array}{c}\text { Group } 2 \\
(\mathrm{~N}=1002) \\
\mathrm{n}(\%)\end{array}$ & p-value* \\
\hline \multicolumn{5}{|c|}{ Territory (regardless of side) } \\
\hline Carotid & $222(9.5)$ & $138(10.5)$ & $84(8.4)$ & 0.03 \\
\hline VB & $23(1.0)$ & $18(1.4)$ & $5(0.5)$ & 0.03 \\
\hline Unknown & $14(0.6)$ & $11(0.8)$ & $3(0.3)$ & 0.06 \\
\hline \multicolumn{5}{|l|}{ Nature } \\
\hline Ischaemic & $166(7.1)$ & $110(8.3)$ & $56(5.6)$ & 0.005 \\
\hline Haemorrhagic & $22(0.9)$ & $12(0.9)$ & $10(1.0)$ & 1.0 \\
\hline Unknown & $71(3.0)$ & $45(3.4)$ & $26(2.6)$ & 0.1 \\
\hline Lacunar & $25(1.1)$ & $17(1.3)$ & $8(0.8)$ & 0.3 \\
\hline Arterial & $147(6.3)$ & $100(7.5)$ & $47(4.7)$ & 0.003 \\
\hline Cardio-embolic & $33(1.4)$ & $21(1.6)$ & $12(1.2)$ & 0.2 \\
\hline Disabling & $77(3.3)$ & $53(4.0)$ & $24(2.4)$ & 0.03 \\
\hline Non-disabling & $109(4.7)$ & $67(5.0)$ & $42(4.2)$ & 0.2 \\
\hline Any & $259(11.1)$ & $167(12.5)$ & $92(9.2)$ & 0.002 \\
\hline
\end{tabular}

* From Cox proportional hazards model, adjusting all other baseline variables listed in table 1 
Table 4: Hazard ratio (HR) of stroke, by baseline characteristics

\begin{tabular}{|c|c|c|c|c|c|c|c|c|}
\hline \multirow[b]{2}{*}{ Category } & \multicolumn{4}{|c|}{ Univariate analysis } & \multicolumn{4}{|c|}{ Multivariate analysis } \\
\hline & HR & $95 \% \mathrm{Cl}$ & $\mathrm{X}^{2}{ }_{1}$ & p-value & HR & $95 \% \mathrm{Cl}$ & $\mathrm{X}^{2}{ }_{1}$ & $p$-value \\
\hline Group 1 vs 2 & 1.50 & $1.16-1.93$ & 9.7 & 0.002 & 1.51 & $1.17-1.95$ & 9.8 & 0.002 \\
\hline Men vs Women & 1.10 & $0.85-1.42$ & 0.5 & 0.5 & 1.06 & $0.82-1.39$ & 0.2 & 0.6 \\
\hline Age (per 10 years increase) & 1.18 & $1.00-1.39$ & 3.7 & 0.05 & 1.23 & $1.03-1.46$ & 5.2 & 0.02 \\
\hline Ipsilateral stenosis (per $10 \% \uparrow$ ) & 0.97 & $0.87-1.07$ & 0.4 & 0.5 & 0.94 & $0.85-1.05$ & 1.3 & 0.3 \\
\hline Contralateral stenosis vs no & 1.11 & $0.85-1.46$ & 0.6 & 0.4 & 1.14 & $0.87-1.49$ & 0.8 & 0.4 \\
\hline Diabetes vs no & 1.60 & $1.21-2.12$ & 10.9 & 0.001 & 1.64 & $1.23-2.17$ & 11.7 & 0.0006 \\
\hline Cardiac disease vs no & 1.17 & $0.90-1.51$ & 1.4 & 0.2 & 1.09 & $0.84-1.41$ & 0.4 & 0.5 \\
\hline Hyperlipidemia vs no & 0.97 & $0.72-1.30$ & 0.05 & 0.8 & 1.03 & $0.76-1.39$ & 0.03 & 0.9 \\
\hline Hypertension vs no & 1.26 & $0.89-1.79$ & 1.7 & 0.2 & 1.16 & $0.82-1.66$ & 0.7 & 0.4 \\
\hline Immediate CEA vs Deferral & 0.67 & $0.52-0.86$ & 10.0 & 0.002 & 0.66 & $0.52-0.85$ & 10.5 & 0.001 \\
\hline
\end{tabular}


Figure 1

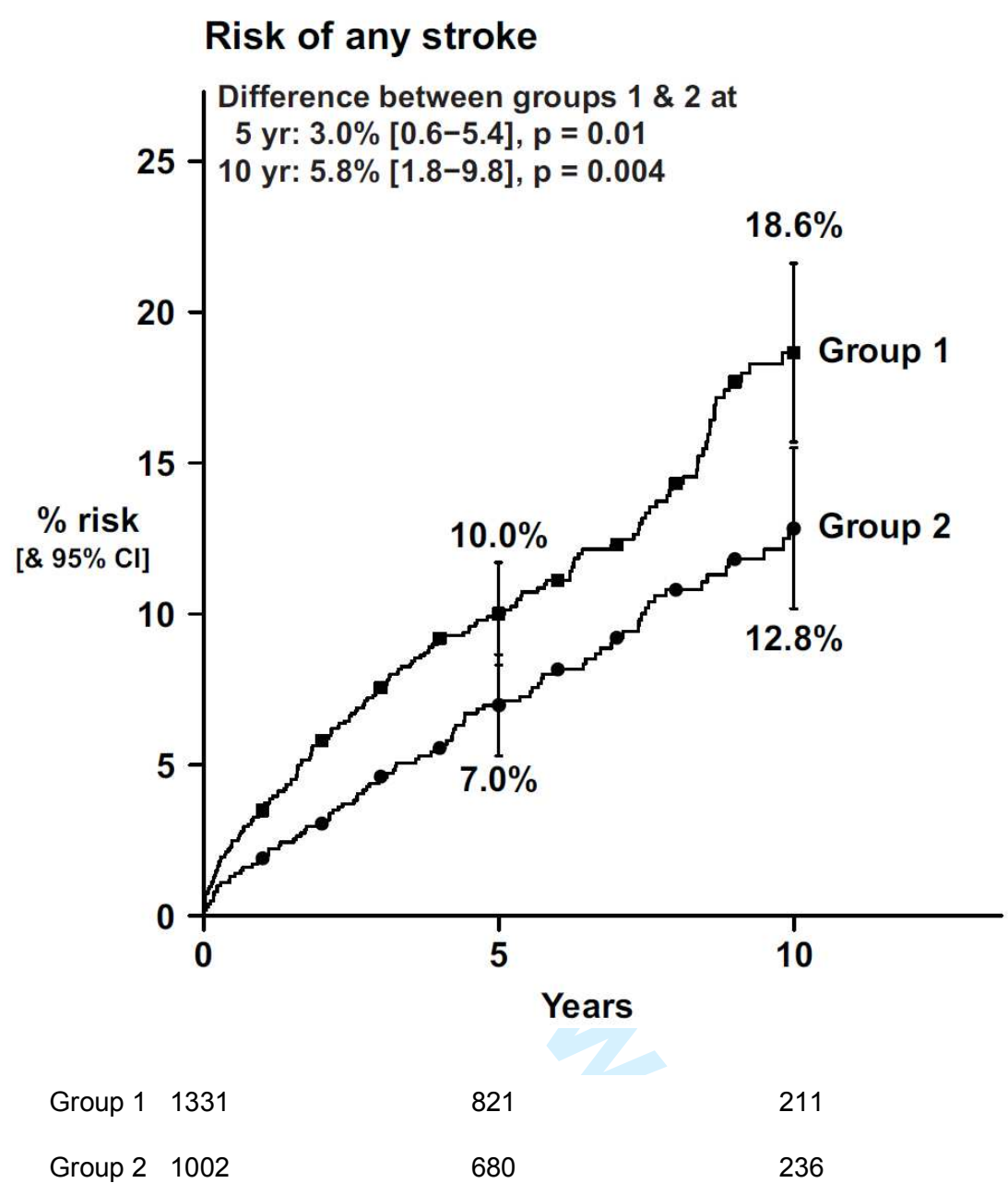


Figure 2

Risk of any stroke or vascular death

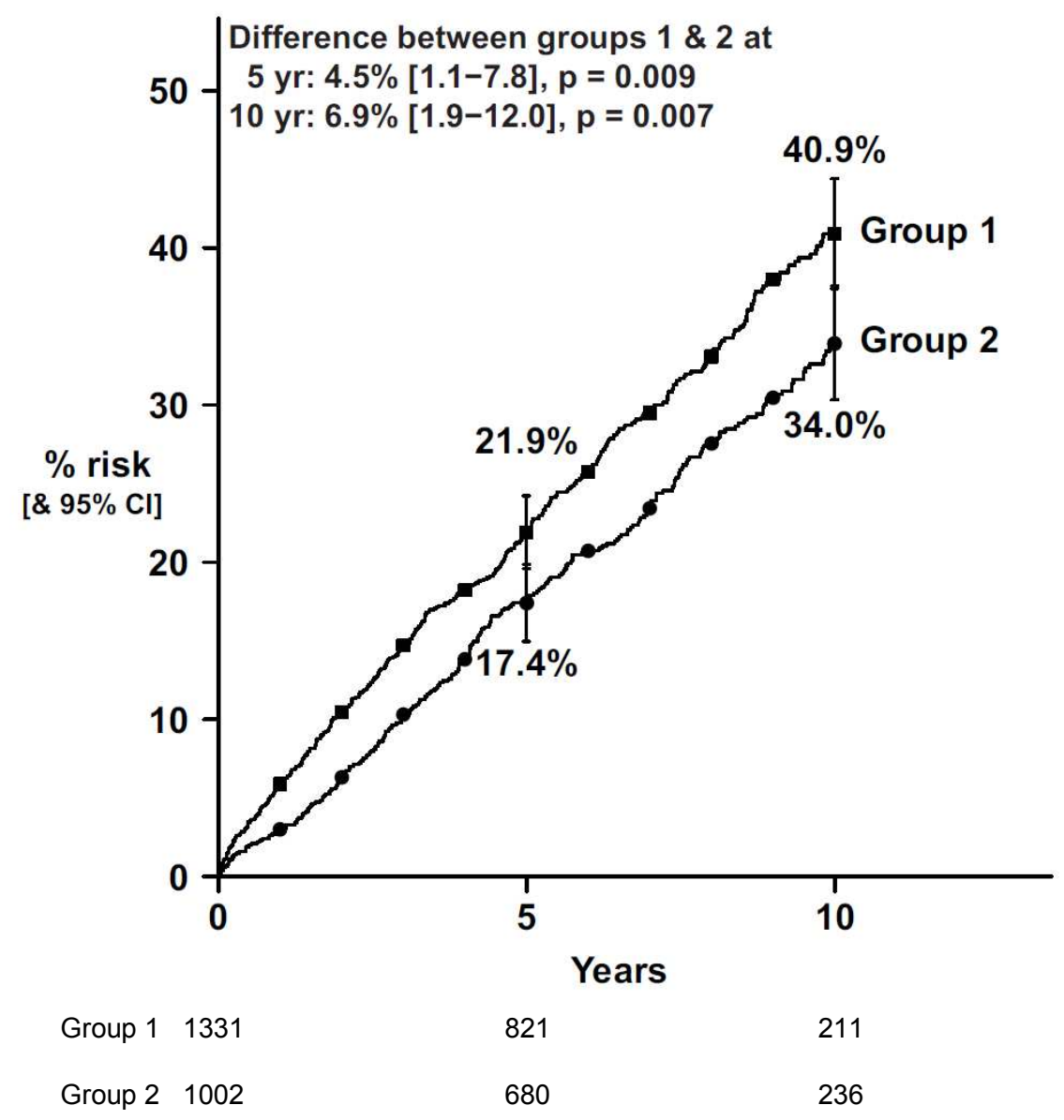

